\title{
14
}

\section{PhD students and integrative research}

\author{
Gary Fry", Bärbel Tress ${ }^{\# \#}$ and Gunther Tress ${ }^{\# \#}$
}

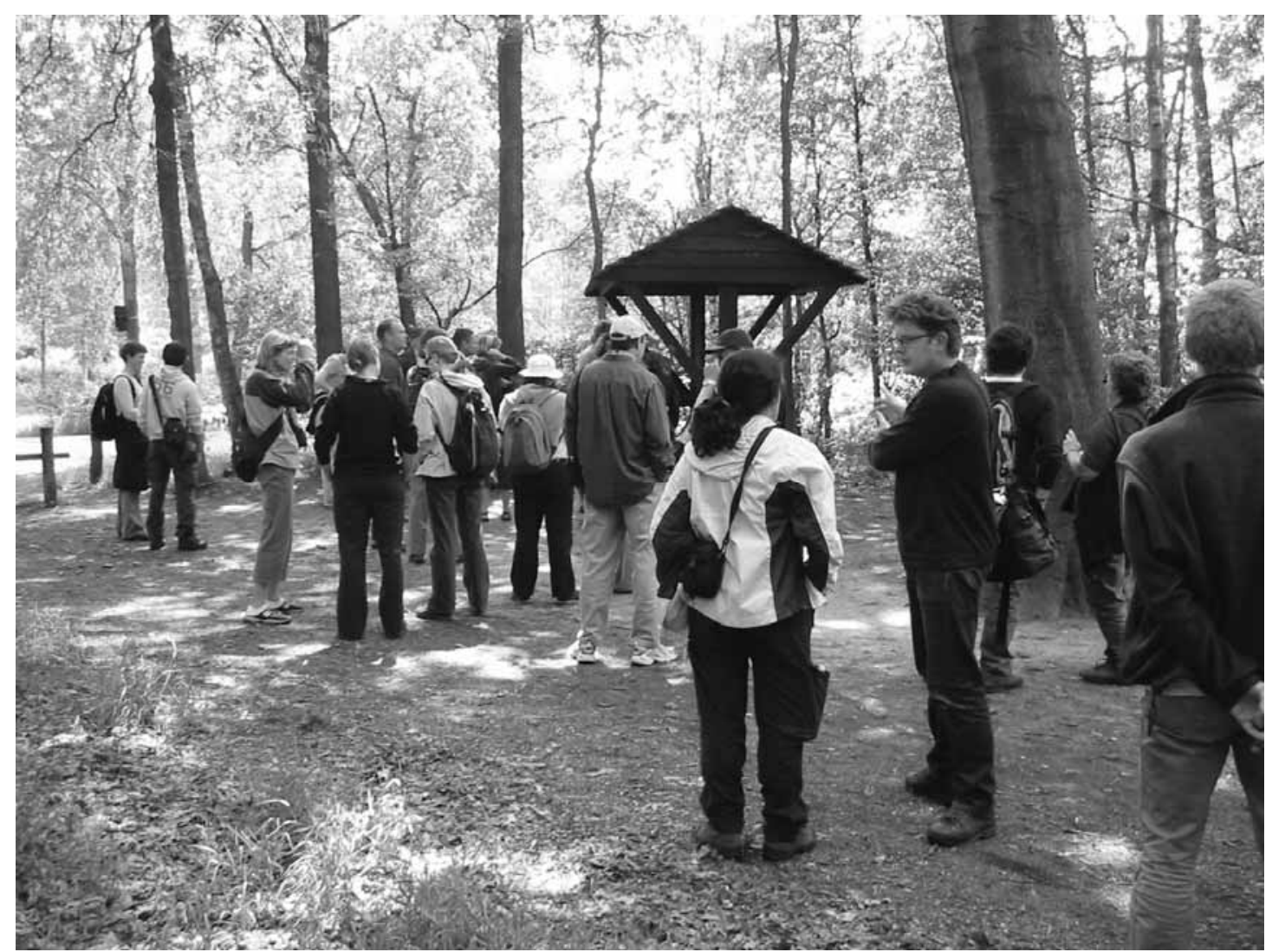

\section{Abstract}

The training of $\mathrm{PhD}$ students is currently very dynamic and varies widely from place to place. We present some examples of this variation and comment on how it may affect the way $\mathrm{PhD}$ students cope with integrative studies. Our focus is on the training needs of $\mathrm{PhD}$ students studying integrative research questions and their need for support from both supervisors and the wider institutional infrastructure. The role of supervisors seems key to the success or failure of integrative $\mathrm{PhD}$ projects. We find evidence that the disciplinary background, interest and motivation of the supervisor have much influence on research outcomes, in terms of the quality and whether $\mathrm{PhD}$ studies are completed on time (or at all). One clearly growing trend in $\mathrm{PhD}$ training is

\footnotetext{
\# Institute of Landscape Planning, Norwegian University of Life Sciences, P.O. Box 5029, N-1432 Ås, Norway. E-mail: gary.fry@umb.no

\# Land Use Planning Group, Department of Environmental Sciences, Wageningen University, Generaal Foulkesweg 13, NL-6703 BJ Wageningen, The Netherlands. E-mail: tress@tress.cc, http://www.tress.cc
} 
the inclusion of coursework, and more recently the inclusion of training in transferable skills aimed at easing the flow of doctoral students into the wider job market since the majority of $\mathrm{PhD}$ students will not end up in academic appointments. PhD students represent major academic and financial investments and contribute to much of the original research in universities. To help $\mathrm{PhD}$ students we need to guide them through the many choices of method and theoretical approaches, a guide that builds on existing knowledge of what works and does not work under different conditions and one that results in the generation of new integrative knowledge.

Keywords: doctoral students; research training; interdisciplinary; transdisciplinary; supervision

\section{Introduction: What is a PhD student?}

In many university departments it is the PhD students who do much of the research and scientific publication. It is also the $\mathrm{PhD}$ students who bring a youthful, challenging stimulus to departments. But what is a PhD student? We use the term $\mathrm{PhD}$ student to include all students registered for a doctoral degree, even though the title of the degree may vary between disciplines and universities. The $\mathrm{PhD}$ (Doctor of Philosophy) is the highest academic degree that can be awarded. It is a 'licence to teach' as a member of faculty and also implies that the holder of the degree has a command of the field of study (Phillips and Pugh 2000). If we try to refine the definition of a $\mathrm{PhD}$ student in more detail, we quickly find that this detail varies greatly between countries and between academic disciplines within countries (see Sadlak 2004). These differences appear to be getting less as both student mobility and international agreements smooth out such variation.

Today, most descriptions of $\mathrm{PhD}$ study programmes (as found on university web pages) include words to the effect that a $\mathrm{PhD}$ study should make a significant contribution to the field of study through independent investigation. A $\mathrm{PhD}$ study is, above all else, a research training. PhD students should be able to demonstrate their research skill through an independent contribution to the relevant knowledge culture. In a study of how experienced examiners assess PhD theses, Mullins and Kiley (2002) found that the development of skills and attitudes necessary for the student to operate as an independent researcher along with the production of an acceptable thesis were the goals of a PhD programme. The main characteristic of a good $\mathrm{PhD}$ thesis was scholarship, which examiners defined as originality, coherence and student autonomy. In addition, a well-argued, logical progression of ideas in the thesis was highly valued by examiners.

$\mathrm{PhD}$ students working on integrative (= interdisciplinary or transdisciplinary) research vary more than their disciplinary counterparts. These students may have any one of a wide range of subject backgrounds and sometimes have taken more than one education. In landscape research, we notice an increasing number of doctoral studies applying integrative research concepts. The range of student backgrounds in these studies may span from visual-perception studies to ecology, from landscape history to resource economics or from philosophy to hydrology. What they have in common is the aim of bridging disciplines to develop new and integrative knowledge. We raise the question of whether this is a realistic task for a PhD student? This is a fair and relevant question to ask, and one that may not always result in a positive answer. The science of integrative research is at a stage of development where we may not always be able to offer appropriate methods or underlying theory. Integrative projects can include a greater degree of insecurity and researchers face unexpected situations that 
are difficult to handle because of a general lack of experience with successful integration. In addition to needing robust research skills, integrative projects also require sound managerial and communicative abilities to facilitate the integration process. As a result, integrative research may not be the best choice for a research training (see also Golde and Gallagher 1999).

Are $\mathrm{PhD}$ students currently well suited to take on the challenges of integrative research? If not, then what type of training might they need to prepare them for this venture? The discussion about $\mathrm{PhD}$ students and integrative research is represented by opposing views concerning the role of students in integrative, especially transdisciplinary, research efforts (Fry 2001). In short, the debate centres on whether young researchers who are still learning research methods and background theory are the best people to undertake the challenge of integrative research. Some believe they are, arguing that they have not yet been immersed in disciplinary cultures and hence will be more open to integration. Others are more sceptical, and feel that PhD students lack research experience and especially of working in depth, often at the edge of knowledge. These factors make it difficult and often impossible to achieve a high level of integration at anything more than superficial level. Whichever of these views is correct, we have yet to see, time will tell. In the meantime, we should try to learn from the many PhD students around the world deeply involved in different aspects of integrative research. Studying their progress may provide us with very valuable information on what works and what does not in different contexts.

In this chapter we address some of the current trends and challenges of a doctoral study in general and in integrative research in particular. We start with introducing the changing profile of $\mathrm{PhD}$ students before reporting on different cultures of $\mathrm{PhD}$ supervision. Following this we discuss education needs for integrative research as well as career perspectives and needs for transferable skills for a life after the $\mathrm{PhD}$. We close with a brief checklist for PhD students to increase their awareness of the many important decisions that will arise during the course of a $\mathrm{PhD}$ study in integrative research.

\section{The changing profile of the PhD student}

In most countries, the number of new doctoral students in science and engineering is increasing (see Figures 1 and 2). However, the exact number of doctoral students is unknown because there is no central register. National research councils estimate figures based on the number of completed PhD projects. For instance, Germany has about 100,000 - 150,000 doctoral students, UK 100,000, France 66,000, Italy 25,000, Austria 15,000 and Greece 7,500. The characteristics of these PhD students vary greatly from place to place as does the nature of their training. The working conditions, size of grant, gender bias and age of research students all vary considerable from country to country (see Sadlak 2004; Eurodoc and Science Next Wave 2005). 


\section{Chapter 14}

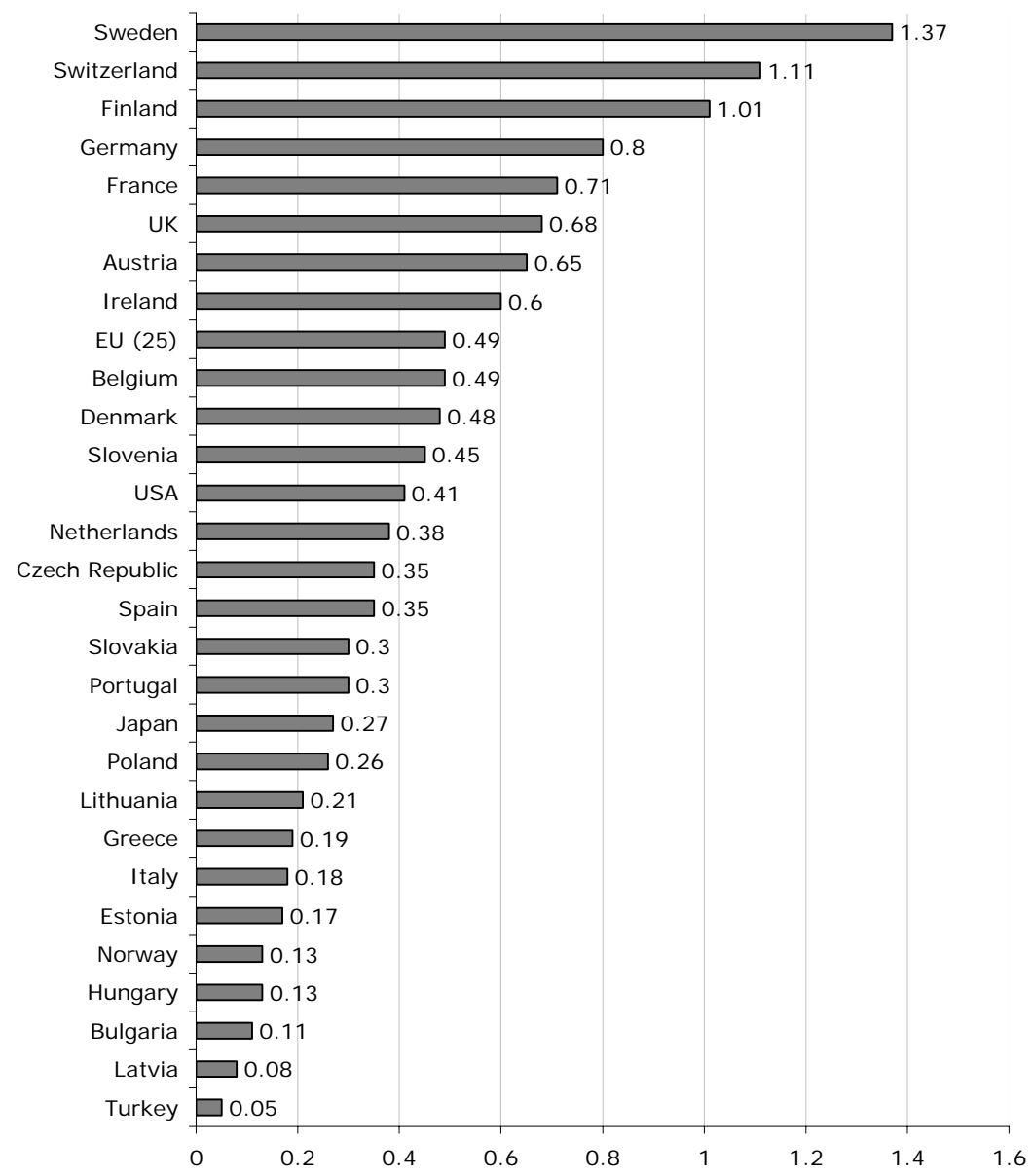

Figure 1. New PhDs per thousand population aged 25-34 in 2001 (Source: European Commission 2003a)

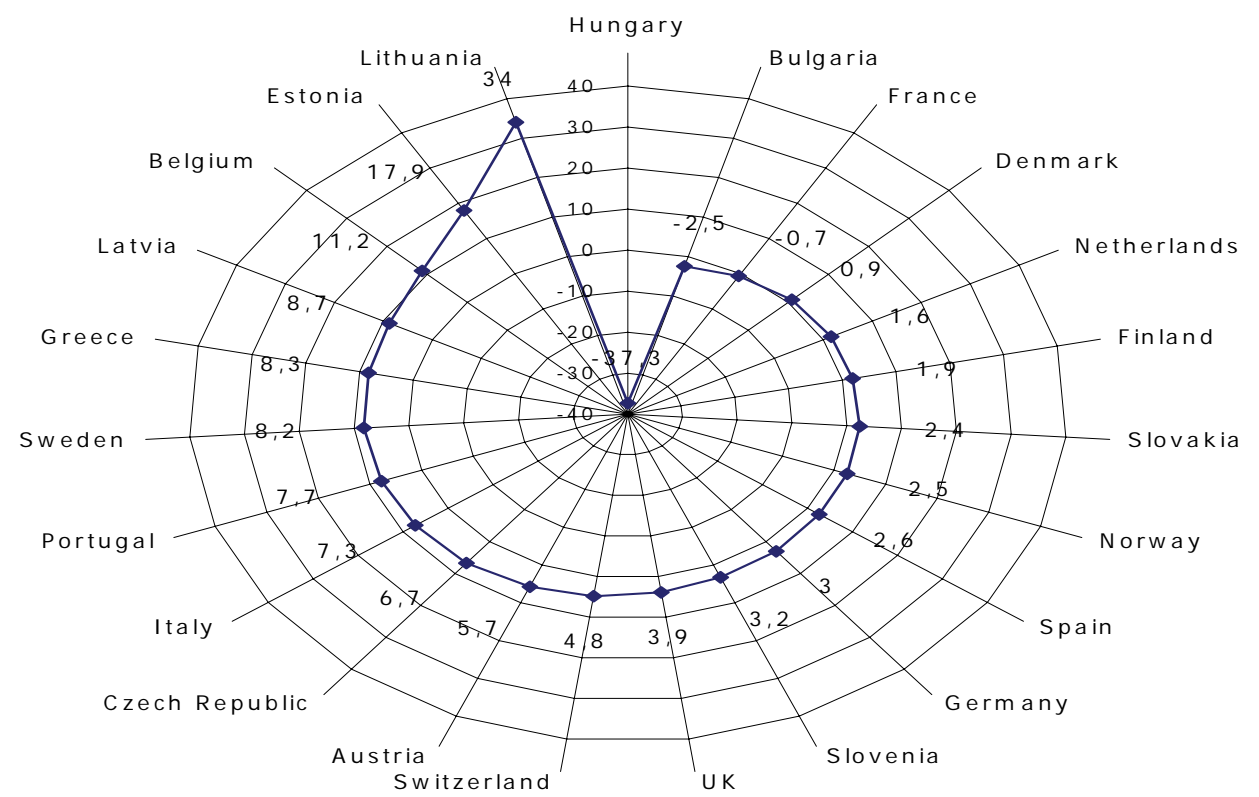

Figure 2. Annual average growth rates (\%) in new PhDs in selected countries between 1998 and 2001 (Source: European Commission 2003a) 


\section{Gender issues}

The proportion of $\mathrm{PhD}$ students who are women is increasing in most subjects. In Scandinavia, this has resulted in ca $50 \%$ of all $\mathrm{PhD}$ students being female. In many subject areas, women now dominate the recruitment statistics for PhD studentships but are still to make a major contribution in the typical male-dominated subjects such as physics, engineering and computing. The relatively low proportion of female university staff (European average of ca 30\%, see European Commission 2003b) is even lower at senior and professor levels in most faculties (European average ca 14\%, http://europa.eu.int/comm/research/science-society/women/wssi/downindi_en.html).

This demonstrates that the process of equality is difficult to achieve and progresses only very slowly. There has been a heated debate on the most effective ways to alter this situation, such as fast-track posts for women researchers, special grants to help women stay in academia at post-doctoral level and the establishment of female-only professorships. It is too early to generalize from the results of these experiments but there is evidence that they are having some success even though it will take a long time before such measures work through to senior academic appointments (see also http://www.eurodoc.net/workgroups/gender/index.php). As there is no central registration, we do not have figures on the proportion of female $\mathrm{PhD}$ students in landscape research, but at $\mathrm{PhD}$ courses they are often in the majority.

\section{Payment and infrastructure}

In the UK, PhD students receive a grant of ca. $€ 13,500$ per year and in Germany it is about the same. This is in sharp contrast to Scandinavia, which pays PhD students an average of ca. €30,000 per year (see Table 1 for net monthly income of $\mathrm{PhD}$ students in selected countries). But the differences do not stop at money, they also include differences in the status and infrastructure afforded $\mathrm{PhD}$ students, as well as in their role in departmental and university life. Depending on country, type of grant and university, PhD students may have the status of an employee, which usually covers social rights to the standards of every worker in that country (for instance in The Netherlands and Scandinavia), or they may have student status, which lacks many of these social rights. Such differences are of significance for the success of integrative projects since these make higher demands for institutional support measures. In universities where $\mathrm{PhD}$ students have serious financial worries and low status, it may be more difficult to obtain the resources necessary to support integrative teams, e.g. through regular meetings, networking etc. However, a large involvement of $\mathrm{PhD}$ students in a department through high teaching loads and other departmental duties may not always benefit the research training.

Table 1. Net monthly income of doctoral students in selected countries in 2003 (Source: Eurodoc, www.eurodoc.net)

\begin{tabular}{lrlr}
\hline Country & EUR & Country & EUR \\
\hline Belgium & 1500 & Norway & 3050 \\
Denmark & 1650 & Portugal & 980 \\
France & 1250 & Russia & 50 \\
Germany & 1000 & Slovenia & 800 \\
Hungary & 315 & Spain & 850 \\
Ireland & 700 & Sweden & 1800 \\
Italy & 840 & Switzerland & 3000 \\
Netherlands & 1300 & UK & 1000 \\
\hline
\end{tabular}




\section{Completion of a PhD study}

There are many geographical and disciplinary differences in every aspect of completing a $\mathrm{PhD}$ study from the age of students completing, the percentage completing, the form of thesis and the proportion of students going on to academic careers. Some countries such as the UK tend to have earlier starting and finishing ages than most of Europe. English students can start a PhD study with a Bachelor's degree and complete their $\mathrm{PhD}$ by the time they are 24. This is less common now than earlier, and students are urged to take a Master's degree in their specialized area first. On average, students start their PhD study in the UK at the age of 24 and end around 28. In Italy they start around 26.5 years and in Germany and Austria around 28 (Eurodoc and Science Next Wave 2005). As in the USA, it is becoming more and more common in Europe to have taken one's Bachelor's degree in one university, Master's in another and $\mathrm{PhD}$ in a third.

How long it takes to achieve a $\mathrm{PhD}$ also varies greatly between countries and disciplines. In a report from the Eurodoc project (Eurodoc: Gathering of Evidence and Development of a European Supervision and Training Charter) there was clear evidence that the three- to four-year PhD study was becoming the standard throughout Europe as far as financing and registration are concerned. Most $\mathrm{PhD}$ theses are completed the year following the formal deadline; average completing time for $\mathrm{PhD}$ students in Austria and UK is three years and eight months; also in Germany and Italy completion time is between three and four years. Average length for French PhD students is four years, in Spain four years and four months. Swedish students took longer averaging six years to complete but this is rapidly going down, a trend related to stricter rules governing $\mathrm{PhD}$ studentships that are only financed for a maximum of four years. The Netherlands is slowly moving away from the concept of the PhD being a 'lifetime project' with students taking up to ten years to complete. At present, only $12 \%$ of $\mathrm{PhD}$ students in The Netherlands finish within the four years they are employed as doctoral students (Eurodoc and Science Next Wave 2005).

A British study on completion of $\mathrm{PhD}$ students revealed that financial support from a research council has no significant effect on completion rates, but the subject area does, with arts and languages having lower, and science and engineering having higher completion rates than the social sciences (Booth and Satchell 1995). Van Ours and Ridder (2003) found that the time taken for graduate education was an important indicator for completion rates of a $\mathrm{PhD}$ student. Students who are likely to take a long time to graduation are also more likely to drop out. Drop-out rates are in general difficult to determine and vary a lot between countries: France 35\%, The Netherlands $25 \%$, Spain up to $87 \%$, and Italy $18 \%$, which may be partly explained by the different status of a doctoral study in these countries (Eurodoc and Science Next Wave 2005).

\section{Format and assessment of PhD theses}

The format and assessment of a PhD thesis are also more variable than one might think. One of the biggest changes under way in the format of $\mathrm{PhD}$ theses is the move away from monographs to a collection of scientific papers. Some subject areas, particularly in the natural sciences, have, to a high degree, adopted the collection of papers as the standard format. Proponents argue that the currency of research is the published paper and therefore it should be the aim of a PhD training to help students write and publish scientific papers. In other subject areas, such as the humanities, the monograph still dominates, and is often a more suitable medium. For those disciplines where publications are seen as a quality control criterion, examiners look favourably on theses that contain published or submitted papers. Acceptance in a reputable peer- 
reviewed journal is seen as a very positive sign by examiners (Mullins and Kiley 2002).

Another important difference in the assessment of $\mathrm{PhD}$ theses between disciplines relates to whether it is the text of the thesis (the product) that is being examined, or the student and the process towards development of a researcher (Demeritt 2004). Mullins and Kiley (2002) found that examiners from the humanities strongly held the belief that it is the text (as it stands) that is being examined. In contrast, they found that examiners from the sciences were more concerned with examining the student and his/her potential rather than the written thesis. This difference places different emphasis on the role of the oral examination; either as a defence of the written word or as an evaluation of the student as a potential researcher. These findings identify yet another area where the integrative $\mathrm{PhD}$ student can fall between opposing knowledge cultures leading to conflict and frustration. Where do we find examiners suited to judge the quality of integrative research? How can we combine the different assessment styles of the humanities and sciences in the appraisal of integrative research efforts? Being aware of the differences is a major step in coping with the differences. Much of this work and responsibility to ensure an equitable examination for integrative $\mathrm{PhD}$ theses will fall into the lap of the supervisor or supervisory team.

\section{The role of the supervisor}

The most controversial aspect of $\mathrm{PhD}$ training is the role of the supervisor. This role is yet another of the factors that vary considerably from country to country and from discipline to discipline. In the new code of practice for post-graduate degrees in the UK (Quality Assurance Agency for Higher Education 2004) we find the need for professional training for supervisors highlighted. The report recommends that $\mathrm{PhD}$ students are allocated at least one supervisor and that this person (a) is trained to supervise, and (b) has expertise in the field of the study. This will be a problem for integrative research where we need qualified supervisors not only in specific disciplines but also supervisors to guide students through the integration process. The lack of 'off the shelf' methods and a solid theoretical anchoring for integrative research intensifies the problem. The use of supervisory teams will be necessary to improve the support necessary to help $\mathrm{PhD}$ students through integrative studies.

\section{Disciplinary cultures and supervision}

One of the most detailed empirical investigations of $\mathrm{PhD}$ supervision is that by Cullen et al. (1993). In their 300-page-long report studying $\mathrm{PhD}$ supervision in Australia, they point to many significant disciplinary differences in $\mathrm{PhD}$ supervision. They found that little previous research has focused on the relationship between knowledge cultures and supervisory practice or styles. The evidence they were able to find identifies major differences in supervisory styles between the Arts and the Sciences based on the work of Whittle (1992). They found that the communication styles for the two knowledge cultures affects how academics perceive the purpose of supervision and hence how they supervise students. This results in different patterns of supervision, research output and expectations. Relationships between disciplinary cultures and supervision styles are shown in Table 2 (after Cullen et al. 1993). For integrative research, supervision styles are particularly relevant to $\mathrm{PhD}$ students, especially how different knowledge cultures perceive the degree to which a $\mathrm{PhD}$ education is a training in research methodology and how much a contribution to the 
relevant knowledge culture. These differences make crossing disciplinary boundaries in a PhD study especially vulnerable to misunderstandings and confusion.

The ways different disciplinary cultures result in different supervision styles may cause implicit or explicit resentment between student and supervisor when they do not share the same expectations of the student-supervisor relationship.

Table 2. Supervision styles compared in the Arts and Sciences (Source: Cullen et al. 1993)

\begin{tabular}{lll}
\hline & Arts & Sciences \\
\hline Style: & Hands off & Close \\
Meetings: & Irregular, infrequent & Regular \\
Project: & Individual & Collaborative \\
Relation to supervisor's research: & Unrelated & Closely related \\
Joint publication: & Uncommon & The norm \\
Mentorship: & Rare & The norm \\
\hline
\end{tabular}

Cultural differences may also give rise to different expectations of $\mathrm{PhD}$ supervision. In a study of Asian students in Australia, Chen et al. (2002) found significant differences over important issues that could give rise to tensions. Three of the most important were (1) an understanding of what a 'substantial contribution to the field' meant; (2) what was meant by the concept 'independent research'; and (3) an understanding of how research 'ethics' applied to PhD students. Yet, their supervisors took the interpretations of these same concepts for granted. Cultural differences also affect face-to-face communication with students, resulting in conflicting expectations of students and supervisors. For example, in the above study, the students expected a hierarchical distance to be maintained between student and supervisor, and that students should not challenge the supervisor's ideas. Cooperation and teamwork represented a new way of learning for these students. If $\mathrm{PhD}$ students with cultural expectations that differ widely from the group norms join an integrative project and are expected to work in cooperative groups, we might find misunderstandings and tensions that have little to do with the integrative process but reflect differing cultural expectations.

\section{Education for integrative research}

Education for the future knowledge society presents many and varied challenges. One of these is whether it is possible to identify key skills that will enable $\mathrm{PhD}$ students to cope with the challenges of a dynamic workplace and with moving between different knowledge cultures. The importance of traditional knowledge acquisition in this process and the degree to which the acquisition of key skills can replace this knowledge remain controversial and unresolved. However, the future will undoubtedly see weaker boundaries between disciplines and a wider view of the remit of research in society. Such changes in our learning environments will force us to ensure students develop a critical understanding of what constitutes reliable knowledge.

Trends in education throughout Europe show greater emphasis on project-based learning at school level. And one finds in schools a range of education activities that support integrative approaches. However, things seem to go wrong at university where disciplinary approaches still dominate. It is not that there is a shortage of 
integrative courses at universities, especially in environmental sciences. At graduate level, there are increasing opportunities for students to take courses across departments and to sew together a degree that provides wide perspectives on land management. However, one weakness of many of these courses is that disciplinary experts teach the individual course units. Integration between, for example, ecology and economy units, is often left to the students.

At the research-training level several problem areas remain. Of these, two serious problems are transition problems that currently affect many $\mathrm{PhD}$ students. These are (1) the shortage of supervisors experienced in integrative research and (2) the lack of academic identity felt by research students. There are few experienced supervisors available to take responsibility for research training - they may lack motivation/commitment to interdisciplinarity or have little experience as an interdisciplinary researcher. Both problems will improve but it will take time. In the meantime, we are left with a situation where too many $\mathrm{PhD}$ students struggle with research tasks that their supervisors cannot tackle. In our INTELS research we have found that interdisciplinary studies may be a hard internship, one that may lead to poorer chances of completion or longer time to complete (Tress, Tress and Fry 2005). Our surveys show that $\mathrm{PhD}$ students in integrative projects take longer than average to complete their studies. Only about one third of the surveyed PhD students involved in integrative research had finished their study within the agreed time, about 18\% finished in extra time. It took them on average five years to complete the doctoral studies. About half of the surveyed students had, however, not finished their project yet. This may be an especially acute problem for research students in transdisciplinary projects where the solving of a specific practical problem may not involve sufficient research activity or originality to qualify for a $\mathrm{PhD}$.

\section{Supportive environments for an integrated PhD study}

All of the small and not so small variations between countries and disciplines regarding the support infrastructure and supervision of a PhD student help to identify areas where we can improve $\mathrm{PhD}$ education. An important support measure for $\mathrm{PhD}$ students is the provision of any special training needs for students embarking on integrative research. Students are often given the task of integrating knowledge generated by disciplinary experts working in the same project. This situation adds to the difficulties faced by integrative $\mathrm{PhD}$ students, as it places pressure on them to be able to communicate across knowledge cultures. They face the challenge of working in close cooperation with people with conflicting ideas of what constitutes data or an appropriate form of analysis etc. As if this were not enough of a challenge, it may also be that relationships with supervisors are prejudiced by the student's background, e.g., an ecologist joining a team of resource economists or the opposite might cause certain tensions.

Many PhD students work with real landscape management problems. To do this, they become part of a team that may comprise both other PhD students and more senior researchers from different disciplines. These approaches aim to develop new forms of integrated knowledge, knowledge that will better address environmental problems. In many cases, $\mathrm{PhD}$ students involved in integrative research (especially in transdisciplinary approaches) are expected also to interpret research findings and be part of the implementation process, working together with a variety of stakeholders. Creating supportive environments in this context will make extensive demands on the supervisors in the first place, but also on the wider institutional academic culture. It 
will be supervisors who have the daunting task of guiding students through this mire while ensuring that $\mathrm{PhD}$ students get the room to develop their own ideas and academic identity.

Further support may be needed when conflict arises between the practical aims of the integrated project and the PhD programme, placing both student and supervisor in a difficult situation. Courses clarifying the nature of the integrative research process will help both groups as will help with understanding the specific project management challenges. Awareness of the cultural and epistemological differences between knowledge cultures will be of great benefit to $\mathrm{PhD}$ students, increasing their understanding of different research approaches and perspectives. Attentiveness of these perspectives will help $\mathrm{PhD}$ students see the context of the venture they are part of. PhD students in integrative studies may also benefit from courses in key skills related to teamwork, negotiating, communicating etc. that will be of benefit in surviving an integrative project. Supportive environments require both institutional and financial resources to enable $\mathrm{PhD}$ projects to be integrated. An important part of this process is the development of an integration plan that clearly identifies the reasons for and ambition levels of the planned integration along with how it will be achieved.

\section{Life after a PhD study}

Of concern to $\mathrm{PhD}$ students who successfully complete integrative studies is whether or not their integrative thesis will be prized in the job market. Will integrative studies place students at a disadvantage in obtaining a research position at university or in industry when their $\mathrm{PhD}$ is completed? The evidence that we have from the INTELS project does not support any bias against integrative studies - in fact the opposite seems to be the case in landscape research, where far more than $50 \%$ of job announcements call for integrative skills and the majority of researchers state a positive career effect. Similarly, we find that fears over publishing the results of integrative studies are exaggerated. Nevertheless, it may take longer to complete an interdisciplinary study and fewer publications may result from it, and these may cause a student not be seen as well qualified as one with a disciplinary thesis by an appointments board for a disciplinary university position. Similarly, students completing an integrative project may not be seen as attractive for a teaching position where the new appointee will be responsible for specific disciplinary course units. Such career perspectives should be discussed openly with $\mathrm{PhD}$ students to match student wishes and job prospects as part of a personal development plan. The advantages of an integrative $\mathrm{PhD}$ and the potential job market should be made clear to students.

The inclusion of coursework in the $\mathrm{PhD}$ training is standard practice in Scandinavia but a more recent phenomenon in the UK. This may in part reflect the broader base of Bachelor's and Master's level courses in Scandinavia. It is also a response to the increasing population of PhDs that will not find permanent research positions. Accurate figures are difficult to obtain, but it is estimated that only about $10 \%$ of UK PhD students and $35 \%$ in France will remain in university research careers (Eurodoc and Science Next Wave 2005). If this is so, then the inclusion of transferable skills in the training of $\mathrm{PhD}$ students will help them in the wider job market and provide a better apprenticeship for a modern university career. As well as subject-specific courses relevant to the student's study, teaching skills, interdisciplinary skills, problem solving, communication, media, business methods, 
intellectual property rights, advanced IT skills, technology transfer and enterprise skills have been discussed in this context (see Pace and Danali 2002; Smith, PedersenGallegos and Riegle-Crumb 2002; and Demeritt 2004 as well as The NewRoute PhD at http://www.grad.ac.uk).

The UK-based national review of emerging practices in the use of 'Personal Development Planning' for postgraduate researchers provides a further example of the increasing interest in providing activities aimed at improving skills and experience of $\mathrm{PhD}$ students (see http://www.grad.ac.uk). The review found that supervisors (or supervisory teams) are seen by $\mathrm{PhD}$ students as the key to the quality of their experience, progress, achievement and learning, including the process of personal development planning. This further emphasizes the importance of the role of the supervisor from project concept to life after a PhD study.

\section{Conclusion}

Integrative research can be an interesting but also a threatening process for a doctoral study. It can clearly broaden the scope of a PhD study and may be successful as long as realizing integration does not become the only goal in the study. We highly recommend $\mathrm{PhD}$ students to think about the opportunities and consequences of becoming involved in integrative studies, both as a career and personally. Wherever possible, colleagues, supervisors or friends should be consulted to gain as clear a picture as possible of what is expected from young researchers in such projects. Once the decision has been made in favour of an integrative approach, we need to make sure the levels of support and infrastructure are sufficient. This includes decisions regarding having one supervisor or a supervisory team. Several countries have made supervisory teams compulsory.

A difficult but important question is: where will the PhD degree lead you? Are you aiming at an academic career as a researcher or do you prefer a professional career outside academia? This has great influence on how you plan and set up your PhD study. Think about how you are going to achieve integration in your project. Are you preparing a thesis or a collection of papers? What is important for you, the product you have at the end of your $\mathrm{PhD}$ study, the process you are going through, or both? Will you gain skills that you can use in the workplace? Select your supervisor carefully, and examine whether you will be joining an active research group. Being part of a research group has many practical advantages for students joining rapidly developing fields through rapid access to the literature, methods and the security of belonging to a knowledge culture.

\section{References}

Booth, A.L. and Satchell, S.E., 1995. The hazards of doing a PhD: an analysis of completion and withdrawal rates of British PhD students in the 1980s. Journal of the Royal Statistical Society A, 158 (2), 297-318.

Chen, S., Absalom, D. and Holbrook, A., 2002. Cultural conflict in PhD supervision. SORTI, University of Newcastle. [http://www.aare.edu.au/conf03nc/ ch03029z.pdf]

Cullen, D.J., Pearson, M., Lawrence, J.S., et al., 1993. Establishing effective PhD supervision. Australian Government Publishing Service. [http:// www.dest.gov.au/archive/highered/eippubs/230/230_full.pdf] 
Demeritt, D., 2004. Research training and the end(s) of the Ph.D. Geoforum, 35 (6), 655-660.

Eurodoc and Science Next Wave, 2005. The Eurodoc Exchange: sharing a vision for the future of research in Europe. Eurodoc. [http://nextwave.sciencemag.org/ feature/eurodocexchange.shtml]

European Commission, 2003a. Key figures 2003-2004: towards a European research area, science, technology and innovation. Office for Official Publications of the European Communities, Luxembourg. [http://europa.eu.int/comm/ research/era/pdf/indicators/benchmarking2003_en.pdf]

European Commission, 2003b. She figures 2003: women and science, statistics and indicators. Office for Official Publications of the European Communities, Luxembourg. [http://europa.eu.int/comm/research/science-society/pdf/ she_figures_2003.pdf]

Fry, G.L.A., 2001. Multifunctional landscapes: towards transdisciplinary research. Landscape and Urban Planning, 57 (3/4), 159-168.

Golde, C.M. and Gallagher, H.A., 1999. The challenges of conducting interdisciplinary research in traditional doctoral programs. Ecosystems, 2 (4), 281-285.

Mullins, G. and Kiley, M., 2002. 'It's a PhD, not a Nobel Prize': how experienced examiners assess research theses. Studies in Higher Education, 27 (4), 369386. [http://www.flinders.edu.au/pgsa/downloads/mullins_\&_kiley_02.pdf]

Pace, C.B. and Danali, S., 2002. Construction Ph.D. level education. Journal of Construction Education, 7 (1), 6-15.

Phillips, E.M. and Pugh, D.S., 2000. How to get a PhD: a handbook for students and their supervisors. 3rd edn. Open University Press, Maidenhead.

Quality Assurance Agency for Higher Education, 2004. Code of practice for the assurance of academic quality and standards in higher education. Section 1: Postgraduate research programmes. 2nd edn. Quality Assurance Agency for Higher Education, Mansfield. [http://www.qaa.ac.uk/academicinfrastructure/ codeOfPractice/section1/postgrad2004.pdf]

Sadlak, J. (ed.) 2004. Doctoral studies and qualifications in Europe and the United States: status and prospects. UNESCO CEPES, Bucharest. UNESCO Studies on Higher Education. [http://www.cepes.ro/publications/pdf/Doctorate.pdf]

Smith, S.J., Pedersen-Gallegos, L. and Riegle-Crumb, C., 2002. The training, careers, and work of Ph.D. physical scientists: not simply academic. American Journal of Physics, 70 (11), 1081-1092.

Tress, B., Tress, G. and Fry, G., 2005. Integrative studies on rural landscapes: policy expectations and research practice. Landscape and Urban Planning, 70 (1/2), 177-191.

Van Ours, J.C. and Ridder, G., 2003. Fast track or failure: a study of the graduation and dropout rates of $\mathrm{Ph} \mathrm{D}$ students in economics. Economics of Education Review, 22 (2), 157-166.

Whittle, J., 1992. Research culture, supervision practices and postgraduate performance. In: Zuber-Skerritt, O. ed. Starting research: supervision and training. The Tertiary Education Institute, University of Queensland, Brisbane, 86-107. 


\section{Additional web resources:}

Eurodoc: http://www.eurodoc.net

Gender equality: http://www.eurodoc.net/workgroups/gender/index.php

Women and Science: http://europa.eu.int/comm/research/science-society/womenscience/women-science_en.html

Science next wave - career directions: http://nextwave.sciencemag.org/europe/

Eurodoc Exchange: http://nextwave.sciencemag.org/feature/eurodocexchange.shtml

Doctoral-student networks: http://www.eurodoc.net/organisations/

European Centre for Higher Education CEPES: http://www.cepes.ro/

Non-academic careers for PhDs: http://chronicle.com/jobs/archive/nonacademic.htm 